Anyone who comes into this environment feels that they are in a place of calm, peace, healing and relaxation, which is a contrast to how our modern society works, which is busy, crazy, fast and noisy.

The findings of this study have important consequences for the evidence-based design of healthcare settings aimed at supporting and empowering users to maintain and enhance their health and well-being. Apart from the benefits to users' mental health and well-being, the symbolic value of holistic versus medical focus, progressive ideals and value placed on clients and employees have strong suggestive power. This, in turn, has resultant economic implications for healthcare providers.

\section{Conclusions}

It appears that time spent in green spaces can provide people with a range of opportunities to enhance their mental health. It can increase people's capacity to self-manage their mental illness and acknowledge the realities of their limitations, and their ability to develop the confidence to seek support from interpersonal relationships as well as from community-based organisations (Osborne et al, 2007). Additionally, the Australian case studies reported here, albeit of limited sample size, highlight the importance of incorporating gardens into healthcare settings and contribute to the green healthcare evidence base accessible to designers, planners, policy makers and hospital administrators who aim to create and support health-promoting settings.
Although the findings cannot be generalised to the wider population, as a whole they suggest that gardens or other green spaces should be included within healthcare plans. In conclusion, while we acknowledge that there are a range of considerations in the allocation of healthcare resources and programmes for maximum benefit, we believe that those programmes which highlight the beneficial outcomes for people with mental illness of 'feeling blue and touching green' are worth implementing.

\section{References}

Corazon, S. S., Stigsdotter, U. K, Nielson, A. G., et al (2010) Developing the nature-based therapy concept for people with stress related illness at the Danish healing forest garden Nacadia. Journal of Therapeutic Horticulture, 20, 35-50.

Osborne, R. H., Elsworth, G. R. \& Whitfield, K. (2007) The Health Education Impact Questionnaire (heiQ): an outcomes and evaluation measure for patient education and self-management interventions for people with chronic conditions. Patient Education Counselling, 66, 192-201.

Osborne, R. H., Batterham, R. \& Livingston, J. (2011) The evaluation of chronic disease self-management support across settings: the international experience of the Health Education Impact Questionnaire Quality Monitoring System. Nursing Clinics of North America, 46, 255-270.

Townsend, M., Henderson-Wilson, C., Warner, E., et al (2015) Healthy Parks, Healthy People: The State of the Evidence 2015. Report prepared for Parks Victoria, School of Health and Social Development, Deakin University, Melbourne. Available at http:// www.hphpcentral.com/article/global-research-compilation-provesstrong-link-between-nature-and-human-health (last accessed September 2017).

van den Berg, A. E., Maas, J., Verheij, R. A., et al (2010) Green space as a buffer between stressful life events and health. Social Science and Medicine, 70, 1203-1210.

Velarde, M. D., Fry, G. \& Tveit, M. (2007) Health effects of viewing landscapes - landscape types in environmental psychology. Urban Forestry and Urban Greening, 6, 99-212.

\section{THEMATIC} PAPER

\title{
Horticultural therapy in a psychiatric in-patient setting
}

\author{
Miguel de Seixas, ${ }^{1}$ David Williamson, ${ }^{2}$ Gemma Barker $^{3}$ and Ruth Vickerstaff 4
}

\begin{tabular}{l}
${ }^{1}$ Consultant Psychiatrist, \\
Cambridgeshire and \\
Peterborough NHS Foundation \\
Trust, UK, email miguel. \\
deseixas@cpft.nhs.uk \\
${ }^{2}$ Specialist Occupational \\
Therapist, Cambridgeshire and \\
Peterborough NHS Foundation \\
Trust, UK \\
\hline${ }^{3}$ Specialist Occupational \\
Therapist, Cambridgeshire and \\
Peterborough NHS Foundation \\
Trust, UK \\
\hline${ }^{4}$ Advanced Occupational \\
Therapist, Cambridgeshire and \\
Peterborough NHS Foundation \\
Trust, UK
\end{tabular}

In-patient mental health services have a duty to constantly seek to improve patient experience and to assist in the development of new skills that can aid recovery. Horticultural therapy can be implemented in an economic, social and environmentally sustainable way to achieve those goals.

In the UK, the National Institute for Health and Care Excellence (NICE) is a public body of the Department of Health that provides national guidance and advice on matters relating to health and social care. NICE publishes guidance, advice, quality standards and information services for health, public health and social care. Quality standards are documents that set out the priority areas for quality improvement. In 2011 and 2012 NICE published quality standards on service user experience in adult mental health services (NICE, 2011) and on patient experience in adult care in the National Health Service (NHS) (NICE, 2012). Among other points, these documents stress the importance of access to meaningful activities for people in hospital for mental healthcare that should include creative and leisure activities, exercise, self-care and community access where appropriate, facilitated by trained health or social care professionals (NICE, 2011), as well as of effective interactions with staff (NICE, 2012). 


\section{Studies of the use of green spaces in mental healthcare}

Population studies have pointed to a positive impact of green spaces, with a cumulative association between access to and quality of green spaces and lower scores on measures of psychological distress (Pope et al, 2015), the major determinants being accessibility of the green space, having sufficient green spaces in the neighbourhood and their use for relaxation and for recreation. Similarly, van den Berg et al (2016) have shown a positive association between time in green spaces and better scores on mental health and vitality scales. Nutsford et al (2013) suggested that green spaces are beneficial to mental health, in particular in the case of anxiety and mood disorders, both through people's participation in activities in usable green spaces near to home and in terms of the proportion of usable green spaces in a neighbourhood. Similar positive effects on general health were found by Dadvand et al (2016). Leck et al (2015) looked at the impact of 'care farms' and found that measures of well-being were positively affected by attendance at these, with the health benefits mediated by the farm environment and social interactions becoming increasingly influential the longer the participants attended the care farm.

There is additional evidence suggesting that several therapeutic goals, such as interaction levels and self-esteem, can be achieved by gardening activities (Rappe et al, 2008). These may have a positive role in the longer-term management of mental health, with 'green' interventions increasingly recognised in the promotion of well-being (Webber et al, 2015).

Specifically relevant for an in-patient population is a study that identified the benefits of bringing horticultural therapy into patient spaces in a population with dementia (Lee \& Kim, 2008). Ward garden spaces provide opportunity for graded participation in a number of green activities (Parkinson et al, 2011). A great benefit of these is social inclusion, identified by Caan (2004) as a way to provide a common identity. The psychological benefits of indoor plants in a population of office workers were critically reviewed by Bringslimark et al (2009), with the recognition of the impact on outcomes such as psychophysiological stress.

\section{The Cavell Centre's horticultural therapy model}

The Cavell Centre in Peterborough is one of the main mental health centres in the east of England. Among other clinical services, it lodges five adult mental health in-patient wards catering predominantly for patients, both voluntary and detained, from north Cambridgeshire and the Fenlands who are experiencing an acute deterioration in their mental health. With the awareness of promising outcomes in a variety of studies and of the aforementioned recommendations from NICE, the local acute adult mental health pathway team developed with the available resources a horticultural therapy project for the acute in-patient general adult psychiatry wards. Here we describe our pathways for horticulture therapy, the outcomes and challenges.

\section{Pathways}

Our in-patient wards have different pathways for horticulture therapy:

- plant in your room

- on-ward gardening (individual or in a group)

- on-site garden

- off-site community allotment

- volunteer community gardening

- paid gardening.

These pathways are underpinned by our model of practice: the Model Of Human Occupation (MOHO; Kielhofner, 2008). Our therapists work to improve the patient's occupational performance skills. One of the core themes of this model is that humans are occupational beings and need to 'do', in the sense that there is a need to participate in tasks that offer a sense of self-worth. This model looks at behaviour from three key areas: volition, habituation and performance. The aim is to deliver meaningful and productive activities that can enable patients to develop their horticultural skills, and to do so within the framework of the triple bottom line of economic, social and environmental sustainability (Elkington, 1994).

\section{Outcomes}

As a proxy measure of how well received the project is, we rely on the average number of participants per week. Participation is on a voluntary basis. We also rely on qualitative statements from participants to review the role of the horticultural therapy project in their recovery and make adjustments as necessary, acting on that feedback.

Recent feedback surveys from the off-site allotment group revealed that $83 \%$ of 75 respondents (from a total of 27 documented allotment sessions) rated the group as 'helpful', 'mostly helpful' or 'extremely helpful'. Additional benefits informally reported to the therapy team included a reduction in anxiety and in restlessness, and a feeling of general well-being.

Some comments made by patients concerning the project are quoted below:

\section{Getting off the ward and focusing on something else. \\ Perfect practice for when you go home.}

Thinking about work and looking forward to getting out of here.

Helping out with the garden and being productive.

Beautiful flowers, beautiful garden, beautiful day, beautiful people.

The project contributes to a better experience of the people admitted to our wards at a particularly difficult period of their lives. It also has other associated gains. It strives to be self-sufficient. This includes less purchasing of essential resources, 
reduced travel times and having a low carbon footprint. Produce harvested provides ingredients for cooking sessions, which in turn give an opportunity to teach basic cooking skills.

\section{Challenges and limitations}

We have encountered different challenges that we tried to address through better multidisciplinary work within the ward teams and communication with the in-patients. These include professionals overestimating the abilities or misinterpreting the skill set required for participation, the need for one-to-one input while in a group setting when there is only one facilitator available, the absence of appropriate clothing and footwear, and reduced motivation of some patients, leading to low participation rates at times.

Another limitation is the level of psychiatric disorder in our in-patient population, sometimes incompatible with participation in horticultural therapy due to factors such as reduced concentration, reduced executive function, inability to sustain activity for prolonged periods, reduced strength or stamina, risk of aggression and of absconsion, as well as, at times, intentional or unintentional destruction of the task environment.

The project originally started as a tentative small occupational therapy group running off the ward. Given that horticultural therapy is one of the aspects of treatment on offer among a plethora of intensive interventions available in an in-patient unit, it becomes difficult to measure the particular impact of this specific intervention.

Finally, time limitations and weather can also affect the ability to complete necessary tasks, such as digging over an entire allotment ready for spring.

\section{Conclusion}

The horticultural groups have a positive impact on the care provided, and contribute to the achievement of good vocational and educational outcomes. Patients can work vigorously and energetically or take a steadier approach. Our patients report that the project helps and supports the wider in-patient community, and describe pride and a sense of achievement when returning from these groups. Meaningful and purposeful goals are beneficial to all involved, although doing things just for the pleasure of it is an often-understated gain. Social interaction takes place in all the pathways - with services, peers or members of the public. This helps to tackle social isolation and increase social inclusion, contributing to the individual's recovery.

\section{References}

Bringslimark, T., Hartig, T. \& Patil, G. G. (2009) The psychological benefits of indoor plants: a critical review of the experimental literature. Journal of Environmental Psychology, 29, 422-433.

Caan, W. (2004) Social exclusion and embracement: a helpful concept? Primary Health Care Research and Development, 5 , 191-192.

Dadvand, P., Bartoll, X., Basagana, X., et al (2016) Green spaces and general health: roles of mental health status, social support, and physical activity. Environment International, 91, 161-167.

Elkington, J. (1994) Towards the sustainable corporation: winwin-win business strategies for sustainable development. California Management Review, 36, 90-100.

Kielhofner, G. (2008) Model of Human Occupation: Theory and Application. Lippincott Williams and Wilkinson.

Leck, C., Upton, D. \& Evans, N. (2015) Growing well-beings: the positive experience of care farms. British Journal of Health Psychology, 20, 745-762.

Lee, Y. \& Kim, S. (2008) Effects of indoor gardening on sleep, agitation, and cognition in dementia patients - a pilot study. International Journal of Geriatric Psychiatry, 23, 485-489.

NICE (2011) Service User Experience in Adult Mental Health Services (Quality Standard 14). National Institute for Health and Care Excellence. Available at https://www.nice.org.uk/guidance/ qs14/resources/service-user-experience-in-adult-mental-healthservices-2098485311173 (accessed November 2016).

NICE (2012) Patient Experience in Adult NHS Services (Quality Standard 15). National Institute for Health and Care Excellence. Available at https://www.nice.org.uk/guidance/qs15/resources/ patient-experience-in-adult-nhs-services-2098486990789 (accessed November 2016).

Nutsford, D., Pearson, A. L. \& Kingham, S. (2013) An ecological study investigating the association between access to urban green space and mental health. Public Health, 127, 1005-1011.

Parkinson, S., Lowe, C. \& Vecsey, T. (2011) The therapeutic benefits of horticulture in a mental health service. British Journal of Occupational Therapy, 74, 525-534.

Pope, D., Tisdall, R., Middleton, J., et al (2015) Quality of and access to green space in relation to psychological distress: results from a population-based cross-sectional study as part of the EUROURHIS 2 project. European Journal of Public Health. Epub ahead of print, https://doi.org/10.1093/eurpub/ckv094.

Rappe, E., Koivunen, T. \& Korpela, E. (2008) Group gardening in mental outpatient care. Therapeutic Communities, 29, 273-284.

van den Berg, M., van Poppel, M., van Kamp, I., et al (2016) Visiting green space is associated with mental health and vitality: a cross-sectional study in four European cities. Health Place, 38, 8-15.

Webber, J., Hinds, J. \& Camic, P. M. (2015) The well-being of allotment gardeners: a mixed methodological study. Ecopsychology, 7, 20-28.

\section{Global Echoes}

BJPsych International would like to encourage submissions from medical students, foundation doctors and psychiatry trainees. Those who are beginning their careers in mental health are often involved in high-quality projects or have diverse training and clinical backgrounds that would be stimulating for our readers to discover. They represent a valuable source of knowledge that can help all professionals to keep abreast of what is happening in the field around the world. We would like to receive submissions in the following areas, with a focus on international mental health work: brief literature reviews on mental health policy or services; reports of elective projects in psychiatry or other experiences of working or volunteering abroad; reflective or descriptive pieces about work undertaken or experiences or challenges encountered in working around the world, or in carrying out research in challenging contexts.

Submissions should be between 500 and 1500 words and original pieces. Email ip@rcpsych.ac.uk. Submissions will undergo peer review. See the online BJPsych International guidelines on format and style (http:// www.rcpsych.ac.uk/usefulresources/publications/journals/submitpapers. aspx). 